\title{
NABH accreditation standards in perceptive of panchakarma clinics and hospitals - a review.
}

\author{
Kubal Madhuri Prakash*', Belge Archana Raman ${ }^{2}$, \\ ${ }^{1}$ PG Scholar, ${ }^{2}$ Professor \& H.O.D.
}

Dept. Of Swasthavritta, Shri Ayurved Mahavidyalaya, Nagpur, India.

*Corresponding author: Mob. No. 8452900646; Email ID- maddykubal22@gmail.com

\section{ABSTRACT}

Ayurveda, emerging as an ancient science of life globally, highlighting India as a native drawing attention from every corner of world. Panchakarma, Yoga Science, Marmachikitsa, Ksharsutra, Rasaushadhi etc. are super specialities of Ayurveda, having no other
alternative at all, are becoming attractions, raising medical tourism in India. In this era, evaluation of organization as per their performance \& quality has become integral part of health sector of India. NABH has established standards by keeping in mind, enhancement of health system \& promotion of continuous quality improvement \& patient safety. Objective- To have a review of NABH accreditation standards in perceptive of Panchakarma clinics \& hospitals. Design- NABH accreditation standards for Ayurveda hospitals second edition is referred to have review in perceptive of Panchakarma clinics \& hospitals. Results-Ayurveda hospital accreditation standards consist of 10 chapters, further divided into 98 standards, incorporation of 590 objective elements. These standards are requirements led by NABH which facilitate safe high quality care. These standards provide framework for quality health facilities, mainly defining Panchakarma facility very precisely, right from documentation to staff awareness. Conclusion- Patients well aware about quality health services, especially in terms of medical tourism expects standard \& safety assurance. These NABH accreditation standards setting benchmark for AYUSH hospitals, helps in enhancing significance in health sector in India.

KEYWORDS- Accreditation, Medical Tourism, NABH, Panchakarma, Quality Assuarance.

\section{Introduction-}

Ayurveda, emerging as an ancient science of life globally, highlighting India as a native drawing attention from every corner of world. Panchakarma, Yoga Science, Marmachikitsa, Ksharsutra, Rasaushadhi etc. are super specialities of Ayurveda, having no other alternative at all, are becoming attractions, raising medical tourism in India. Especially Panchakarma glowing globally, defining many other prospective (wellness, rejuvenation, 
detoxification, relaxation, etc.) other than just curative treatment. A recent trend has shown that people from developed countries are seeking treatment for the health from developing countries.

When it comes to medical tourism patients or health insurance companies, mark of quality assurance \& safety of hospital becomes non-negotiable.

\section{NABH-}

\section{National Accreditation Board for Hospitals and Healthcare} Providers (NABH) is a constituent board of Quality Council of India (QCI), set up to establish \& operate accreditation programme for healthcare organizations.

Objectives-

- Enhance health system

- Promote continuous improvement \& patient safety.

NABH offers accreditation servtes

to Hospitals, Small Health Care Organizations/Nursing Homes, Blood Banks, OST Centres, Wellness centres \& Medical Imaging Services. Accreditation of AYUSH Hospitals is a new initiative of NABH.

\section{Benefits of Accreditation ${ }^{[1]}$}

Benefits for Patients-

Patients are the biggest beneficiary among all the stakeholders. Accreditation results in high quality of care \& patient safety. The patients are serviced by credential medical staff. Rights if patients are respected \& protected. Patient's satisfaction is regularly evaluated.
Benefits for Ayurveda Hospitals-

Accreditation to an Ayurveda Hospital stimulates continuous improvement. It enables hospital in demonstrating commitment to quality care. It raises community confidence in the services provided by the Ayurveda Hospital. It also provides opportunity to healthcare unit to benchmark with the best.

Benefits for Hospital Staff-

The staff in an accredited Ayurveda hospital is satisfied lot as it provides for continuous learning, good working environment, leadership \& above all ownership of clinical processes. It improves overall professional development of clinicians \& Para Medical Staff \& provides leadership for quality improvement with medicine \& nursing.
Finally, accreditation provides an objective system of empanelment by insurance \& other third parties. Accreditation provides access to reliable $\&$ certified information on facilities, infrastructure \& level of care.

\section{NABH Standards ${ }^{[2]}$.}

NABH Standards for Ayurveda hospitals prepared by technical committee contains complete set of standards for evaluation of Ayurveda hospitals for grant of accreditation. The standards provide framework for quality of care for patients \& quality improvement for Ayurveda hospitals. The standards helps to build a quality culture at all level $\&$ across all the function of Ayurveda hospitals. A 
minimum bed strength of 10 beds is essential for a hospital to be considered for the Accreditation Program.

NABH Accreditation Standards for Ayurveda Hospitals has 10 chapters incorporating 94 standards \& 489 objective elements.

\section{Chapter 1- Access Assessment and Continuity Care (AAC)}

Panchakarma perspective-

I. All Panchakarma Services available at hospital or clinic are clearly defined \& prominently displayed.

II. Staff is oriented to these services \& aware about documented policies \& procedure.

III. Documentation regarding registration \& admission process-

- Documented policies and procedure used for admission \& registration of out-patients, patients \& emergency patients with unique identification number.

- Address of Management of patients during non-availability of beds.

- Maintenance record regarding daily bed occupancy with monthly conclusion of occupancy.

- Guidance about the transfer of patients to another facility in an appropriate manner also includes transfer of stable/unstable patients, identifying staff responsible during transfer/referral, providing summary of patient's condition \& treatment given.

IV. Documentation regarding Initial assessment-

- Definite \& documented content of initial assessment for out-patients, in-patients \& emergency patients.
- Determination of who can perform within definite time frame based on patient's need.

- Initial assessment of in-patients documented within $24 \mathrm{hrs}$ or earlier as per patient's condition or hospital policy including identification of medication history of in-patient (relevant AYUSH or another AYUSH system, modern medicine), screening for nutritional needs.

- Documented Care plan (including appropriated preventive aspects of plan), countersigned by doctor in-charge within $24 \mathrm{hrs}$ has to be monitored.

- The Care plan includes desired results of the treatment care or service.

V. Regular reassessment of patients determines their response to treatment \& to plan further treatment or discharge -

All patients are reassessed at appropriate intervals.

Out-patients are informed for their next follow-up (as per panchakarma schedule).

- For In-patients their care plan is monitored \& modified if necessary.

- Staff involvement in direct clinical care document reassessments.

VI. Continuous \& multidisciplinary Patient Care

- During coordinated all phases of care a qualified individual designated as responsible for patient's care.

- Information about the patient's care \& response to treatment is shared, exchanged \& documented during each staffing shift, between shifts, $\&$ during transfers between units/departments.

- The patient's record is available to the authorized care-providers 
to facilitate the exchange of information.

- Documented policies \& procedures guide the referral of patient's to other departments/specialities.

VII. Documented policies \& procedures regarding Discharge process-

- Patient's discharge process is planned in consultation with patient \&/or family.

- Documentation exist for coordination of various departments \& agencies involved in the discharge process (including medico-legal \& absconded cases), patients leaving against medical advice (LAMA) $\&$ patient's being discharged on request.

- A discharge summary is given to all patients leaving the organization (including LAMA patients \& patient's bejng discharged on request).

- Discharge summary contains the patient's name, unique identification number, date of admission, reason for admission, significant findings \& diagnosis, date of discharge, patient's condition at the time of discharge, information regarding investigation results, any panchakarma or any other procedure performed, medication administered, other treatment, follow-up advice, medication \& other instructions in understandable manner, instructions about when $\&$ how to obtain urgent care, in case of death cause of death.

\section{Chapter 2- Care Of Patients (COP)}

Panchakarma perspective
I. Standard guidelines are adopted to guide uniform patient care whenever possible, which reflects applicable laws, regulations \& guidelines.

II. Staff is familiar \& trained with documented policies \& procedures for emergency care during Panchakarma (including admission, discharge or transfer).

III. Adequate access \& space for appropriately equipped ambulance, which is manned by trained personnel.

IV. The ambulance adheres to statutory requirements \& checked on daily basis (mainly equipment, emergency medicines), has a proper communication system.

V. A documented procedure exists for obtained informed consent from the appropriate legal representative for vulnerable group (elderly, physically \&/or mentally challenged \& children).

Documentation of panchakarma procedure-

An informed consent is obtained by Physician prior to Panchakarma procedure.

- Patient shall have pre procedure (panchakarma) assessment \& a provisional diagnosis documented prior to procedures.

- Documentation exist to prevent adverse events like wrong procedure.

- Persons qualified by law are permitted to perform the procedures that they are entitled to perform.

- A brief note regarding procedure is documented prior to transfer of patient from recovery area.

- The physician document the post procedure care plan.

- Adequate area, appropriate facilities \& equipment/instruments are available in the Panchakarma 
therapy \& treatment procedure room.

- Patient, personnel \& material flow conforms to infection control practices.

- Guidelines for various Panchakarma therapy \& other treatment procedures are prepared separately \& adhered.

- Standard precautions \& asepsis is adhered to during the conduct of therapies.

- A quality assurance program is followed for the Panchakarma therapy which also includes surveillance of Panchakarma treatment procedure room.

VII. Documentation for Research activities-

- Documented policies \& procedures guide all research activities in compliance with national \& international guidelines.

- Ethics committee to oversee all research activities, has/the powers to discontinue a research trial when risks outweigh potential benefits.

- Patient's informed consent is obtained before entering them in research protocols.

- Patients are informed of their right to withdraw from the research from the research at any stage \& also of consequences (if any) of such withdrawal.

- Patients are assured that their refusal to participate to participate or withdrawal from participation will not compromise their access to the organization's services.

VIII. There is written order for Pathyahara according to patient's clinical needs.
Chapter 3- Management of Medication (MOM)

Panchakarma perspective-

I. Documented policies \& procedures for pharmacy services, medication usage, storage of medication (guided by sound inventory control practices), prescription of medications (including determines who can write orders), govern patient's self-administration of medications, medication error, adverse drug event.

II. Medication orders are clear, legible, dated, timed, named \& signed, contains the name of the medicine, route of administration, dose to be administered \& frequency/time of administration.

III. Medications are administered by those who are permitted to do so.

IV. Prior to administration patient is identified \& medication, dosage, route, timing is verified \& documented.

\section{Chapter 4- Patient Rights and Education (PRE)}

Panchakarma perspective-

I. Patients \& family are informed of their documented \& displayed rights \& responsibilities in a format \& language that they can understand.

II. Staff is aware of their responsibility in protecting patients \& family rights.

III. Violation of patient \& family rights is recorded, reviewed \& corrective/preventive measures taken.

IV. Patient \& family rights include-

- Address any special references, spiritual \& cultural needs. 
- Respect for personal dignity \& privacy during examination, procedures \& treatment.

- Protection from physical abuse or neglect.

- Treating patient information as confidential.

- Refusal of treatment.

- Informed consent before panchakarma therapy.

- Information on how to voice a complaint.

- Information on the expected cost of the treatment.

- A right to have an access to his/her clinical records.

- Information on care plan, progress \& information on their health care needs.

V. Documented procedure incorporates the list of the situations where informed consent is required \& the process for taking informed consent which includes information regarding the procedure, risks, beneffit alternatives \& as to who perform the requisite procedure in a language that they can understand.

VI. Patient \&/or family are educated in a language $\&$ format that they can understand about foodmedicine interactions, pathyahara \& poshana, safe \& effective use of medications \& the potential side effects of the medications, specific disease process, complications \& preventive strategies.

VII. There is uniform pricing policy in a given setting (out-patient \& inpatient category), the tariff list is available to patients.

VIII. Patient \& family are informed about the financial implications when there is a change in the patient condition or treatment setting.

\section{Chapter 5- Hospital Infection Control (HIC)}

Panchakarma perspective-

I. Documented hospital infection prevention \& control programme is a continuous process $\&$ updated at least once in a year.

II. The hospital has infection control team, which coordinates implementation of all infection prevention \& control activities \& designated infection control officer as part of the infection control team.

III. The organization identifies the various high risk areas \& procedure \& implements policies \&/or procedures to prevent infection in these areas.

IV. The organization adheres to standard precautions at all times, hand-hygiene guidelines, housekeeping procedures, and cleaning, disinfection \& sterilization practices.

An appropriate antibiotic policy providing integrated services with allopathy is established \& implemented.

VI. Laundry -linen management, kitchen sanitation, food handling issues, engineering controls to prevent infections are included in the manual.

VII. Verification of surveillance data is done on regular basis by infection control team.

VIII. Surveillance activities includes monitoring the effectiveness of housekeeping services, compliance with hand hygiene guidelines.

IX. The organization takes action to prevent urinary tract infections, respiratory tract infections, skin infections.

X. Appropriate pre- \& post-exposure prophylaxis is provided to all staff members concerned. 
XI. Adequate \& appropriate personal protective equipment, soaps \& disinfectants are available, accessible (facilities for hand hygiene) \& used correctly.

XII. Proper segregation \& collection of biomedical waste from all patient care areas of the hospital is implemented \& monitored.

XIII. Biomedical waste treatment facility is managed as per statutory provisions or outsourced to authorized contractor.

XIV. Appropriate personal protective measure are used by all categories of staff handling biomedical waste.

XV. The organization conducts appropriate "in-service" training sessions for all staff at last once in a year.

XVI. Documented procedure guides the cleaning, packing, disinfection \&/or sterilization (adequate space available for activities, regular validation tests, established recall procedure when breakdown in the sterilization system is identified) storing \& issue of items.

\section{Chapter 6- Continuous Quality Improvement (CQI)}

Panchakarma perspective-

I. Documented quality improvement programme \& patient-safety programme, which is comprehensive \& covers all the major elements related to quality improvement \& risk management, is developed, implemented \& maintained by a multidisciplinary committee.

II. There is a designated individual for coordinating \& implementing these programme.

III. The programme is communicated $\&$ coordinated amongst all the employees of the organization through proper training mechanism.

IV. Programme is reviewed at predefined intervals \& opportunities for improvement are identified \& updated at least once in a year.

V. The organization adopts \& implements national/international patient-safety goals/solutions.

VI. Monitoring for clinical includes appropriate patient assessment, safety \& quality control programme of diagnostics services, medication management, availability \& content of medical records, infection control activities, panchakarma therapies $\&$ treatment procedures, clinical research, data collection to support further improvements.

Monitoring for managerial includes procurement of medication essential to meet patient needs, reporting of activities as required by laws \& regulations, risk management, utilization of space, manpower \& equipment, patient \& employee satisfaction, adverse events \& never misses, availability \& content of medical records, data collection to support further improvements \& it's evaluation.

VIII. Hospital management makes available adequate resources required for quality improvement programme.

IX. Medical \& nursing staff participates in established system for clinical audit which is documented.

X. The organization has an incident reporting system, process to collect feedback \& receive complaints.

XI. The organization has established processes for intense analysis of defined sentinel events. 


\section{Chapter 7- Responsibilities Of management (ROM)}

Panchakarma perspective-

I. Defined responsibilities of management- responsible for governance

- Lay down the organization's vision \& mission statement.

- Approve the strategic \& operational plans \& organization's budget.

- Approve the organization's budget \& allocate the resources required to meet the organization's mission.

- Monitor \& measure the performance of the organization against the stated mission.

- Establish organization organogram.

- Appoint the senior leaders in the organization.

- Support safety initiatives quality improvement plans.

- Support research activities.

- Address the organization's social responsibility.

II. Scope of services of each department is defined.

III. Administrative policies \& procedures for each department are maintained.

IV. Departmental leaders are involved in quality improvement.

V. The leaders establish the organization's ethical management, which shall be documented.

VI. The organization honestly portrays it's affiliations \& accreditations, the services which it can \& cannot provide \& accurately bills for it's services based upon a standard billing tariff.
VII. The person heading the organization has requisite \& appropriate administrative qualifications \& experience.

VIII. The organization documents employee rights \& responsibilities \& monitors the quality of the outsourced services.

IX. Management ensures proactive risk management across the organization \& provide resources for that.

X. Management ensures that appropriate corrective \& preventive actions are taken to address safety related incidents.

\section{Chapter 8- Facility Management and} Safety (FMS)

Panchakarma perspective-

I. Safety committee coordinates development, implementation \& monitoring of the safety plan \& policies.

Patient-safety devices are installed across the organization $\&$ inspected periodically.

III. Facility inspection rounds to ensure safety are conducted at least twice in a year in patientcare areas \& at least once in a year in non-patient-care areas \& reports are documented.

IV. There is a safety education programme for staff.

V. Up-to-date drawings are maintained which detail the side layout, floor plans \& fire-escape routes.

VI. There is internal \& external sign postings in the organization in a language understood by the patient, families \& community.

VII. The provision of space shall be in accordance with the available literature on good practices (Indian or International 
Standards) \& directives from government agencies.

VIII. Potable water \& electricity are available round the neck \& regularly tested alternate sources provided as a backup for any failure/shortage.

IX. There is a documented operational \& maintenance (preventive \& breakdown) plan.

X. Maintenance staff is contactable round the clock for emergency repairs \& response times are monitored.

XI. For engineering support systems \& Bio-medical equipment management-

- Equipment are selected, updated or upgraded by a collaborative process \& inventoried \& proper $\operatorname{logs}$ are maintained as required.

- There is a documented operational \& maintenance (preventive \& breakdown) plan.

- Qualified \& trained personnel operate \& maintain equipment.

- There is a documented procedure for equipment replacement \& disposal.

XII. There is maintenance plan for water management, electrical systems, heating, ventilation \& air-conditioning.

XIII. Documented procedure govern procurement, handling, storage, distribution, usage \& replenishment of medical gases in a safe manner.

XIV. Regularly tested alternate sources for medical gases, vacuum \& compressed air are provided for in case of failure.

XV. There is an operational \& maintenance plan for piped medical gas, compressed air \& vacuum installation.

XVI. Plans for fire \& non-fire emergencies-
- The organization has plans \& provisions for early detection, abatement \& containment of fire $\&$ non-fire emergencies.

- The organization has a documented safe-exit plan in case of emergencies.

- Staff is trained for its role in case of such emergencies.

- Mock drills are held at least twice a year.

- There is maintenance plan for fire-related equipment.

XVII. The organization implements processes for sorting, labelling, handling, storage, transporting \& disposal of hazardous material.

\section{Chapter 9- Human Resource Management (HRM)}

Panchakarma perspective-

I. The organization maintains an adequate number $\&$ mix of staff to meet the care, treatment \& service needs of the patient.

The required job specifications \& job description are well defined for each category staff.

III. The organization verifies the antecedents of the potential employee with regards to criminal/negligence background.

IV. Documented procedure for recruitment is based on predefined criteria.

V. The induction training for every staff includes-

- Orientation to the organization's vision, mission \& values.

- Awareness on employee rights \& responsibilities.

- Awareness on patient's right \& responsibilities.

- Orientation to the service standards of the organization.

- Awareness of organization's wide documented policies \& procedures as well as relevant 
department/unit/service/program

me's documented

policies/procedures.

VI. Staff is trained on occupational safety aspects.

VII. A documented performance appraisal system (carried out at pre-defined intervals) exists in the organization.

VIII. Performance is evaluated based on the pre-determined criteria.

IX. Documented disciplinary policy \& procedure is based on the principles of natural justice.

X. Documented policies \& procedure for grievance.

XI. A pre-employment medical examination is conducted on all the employees.

XII. Regular health checks of staff dealing with direct patient care are done at least once a year $\&$ the findings/results are documented.

XIII. Occupational health hazards adequately addressed.

XIV. The personal file of each member contains personal REDA REAT. information regarding the staff qualification, disciplinary background, health status, all records of in-service training, education \& results of all evaluation.

XV. Medical professional \& nursing staff permitted by law, regulation $\&$ the hospital to provide patient care without supervision are identified.

XVI. The education, registration, training \& experience of the identified medical professionals \& nursing staff is documented, verified \& updated periodically.

XVII. Medical professionals \& nursing staff are granted privileges to admit \& care for patients in consonance with their qualification, training, experience $\&$ registration.
XVIII. The requisite services to be provided by the medical professionals \& nursing staff are known to them as well as the various departments/units of the organization.

XIX. The education, training \& experience of Panchakarma therapist, Paricharaka are documented, appropriately verified \& updated periodically.

XX. Panchakarma therapist \& Paricharaka are granted privileges care for patients in consonance with their qualification, training, experience $\&$ registration.

\section{Chapter 10- Information Management} System (IMS)

Panchakarma perspective-

I. Policies \& procedures to meet the information needs are documented.

Formats for data collection are standardized.

III. Necessary resources are available for analysing data.

IV. Documented procedures are laid down for timely \& accurate dissemination of data, storing \& retrieving data.

V. Every medical record has a unique identifier.

VI. Organization policy identifies those authorized to make entries in medical record.

VII. Every medical record entry is dated \& timed \& author of the entry can be identified.

VIII. The contents of medical record are identified, documented \& provides an up-to-date \& chronological account of patient care.

IX. Provision is made for 24-hour availability of the patient's record 
to healthcare providers to ensure continuity of care.

$\mathrm{X}$. The medical record contains-

- Information regarding reasons for admission, diagnosis \& care plan.

- The results of tests carried out \& the care provided.

- Operative, Panchakarma \& other procedure performed.

- In case of patient transferred to another hospital, date of transfer, the reason for the transfer $\&$ the name of receiving hospital.

- A copy of the discharge note duly signed by appropriate \& qualified personnel.

- In case of death, a copy of death certificate indicating the cause, date \& time of death.

XI. Care providers have access to current \& past medical record.

XII. Documented policies \& procedures exist for maintaining confidentiality, security \& integrity of information, incorporates safeguarding data/record against destruction \& tampering.

XIII. A documented procedure exists on how to respond to patients/physicians \& other public agencies requests for access to information in the medical record in accordance with the local \& national law.

XIV. Documented policies \& procedures are in place on retaining the patient's clinical records, data \& information, provides expected confidentiality $\&$ security.

XV. The destruction of medical records, data \& information is in accordance with the laid down policy.

XVI. The medical records are reviewed periodically by identified care providers.

XVII. The review uses a representative sample based on statistical principles \& includes records of both active $\&$ discharged patients.

XVIII. The review focuses on the timelines, legibility \& completeness of the medical records \& points out \& documents deficiencies in records.

XIX. Appropriate corrective \& preventive measures undertaken are documented.

\section{Discussion-}

The $1^{\text {st }}$ edition of NABH standard has been in practice for last six years now (2009-15) \& is revised \& up-graded to $2^{\text {nd }}$ edition. The Accreditation Standards of NABH are categorized into chapters according to various aspects e.g. patient's rights \& safety, staff rights \& safety, documentation \& management, patient care, pro forma of services, infrastructure requirements, etc.

\section{In the Chapter 1 Access} Assessment and Continuity Care (ACC), documentation regarding patient's assessment on every stage including registration, admission, and discharge is highlighted. Continuous coordination of all phases of care is expected. Orientation or training regarding patient care in every aspect (informed consent from appropriate legal representatives, well equipped ambulance, transfer of patient, regarding research activities etc.) as per law and guidelines including emergencies during panchakarma, pathyahara written order are stated in Chapter 2 Care Of Patients (COP). Pharmacy services related standards are described in Chapter 3 Management Of Medication (MOM). Important issue like connectivity between staff and patient, patient's family in terms of their rights, financial implications properly explained in Chapter 4 Patient Rights and Education (PRE). Standards described in Chapter 5 Hospital Infection Control (HIC) are revolves around infection 
control policy, antibiotic policy, sanitation surveillance, biomedical waste treatment facility. Quality and safety of hospital is ensured with implementation and coordination of various programme regarding monitoring clinical, managerial units as per Chapter 6 Continuous Quality Improvement (CQI). Administration regulations, their responsibilities about quality assurance, risk management, safety and accreditation are clearly ensured with the help of Chapter 7 Responsibilities Of Management (ROM). Various safety measures, plans, procedures, training standards related with infrastructure, biomedical waste, ventilation given in Chapter 8 Facility Management and Safety (FMS). Chapter 9 Human Resource Management (HRM) comprises of standards of recruitment criteria, staff induction training, pre-employment evaluation, and performance evaluation, documentation of medical professionals and staff etc. Technical aspect documentation (restoration, analy availability, retaining data) noted $/$ in Chapter 10 Information Management System (IMS).

Standards described in all chapters are interlinked and dependent in various ways, but still categorization helps to sort out and understand it thoroughly. This sequential appropriately guides to understand the accreditation standards.

\section{Conclusion-}

National accreditation system for Ayurveda hospitals ensure that hospitals, whether public or private, national or expatriate, play there expected roles in national health system.

NABH has now gone global \& is making its mark internationally. The Accreditation standards of NABH are not expected to be prescriptive, they only lay down the requirements of standards which an Ayurveda hospital can comply.

\section{References-}

1. National Accreditation Board for Hospitals \& Healthcare providers (NABH), General information brochure. 2010.

2. National Accreditation Board for Hospitals \& Healthcare providers (NABH), Accreditation Standards for Ayurveda Hospitals. $2^{\text {nd }}$ edition, April 2016.

3. Rajan R, et al., Biomedical waste management in Ayurveda hospitals- current practices \& future prospectives, J Ayurveda Integr Med (2018). http://dx.doi.org/10.1016/j.jaim.2 $\underline{017.07 .011}$

4. Janmejaya Samal. Health informatics: An offbeat yet attractive career alternative for AYUSH graduates in India. Ayurpharm Int J Ayur Alli Sci. 2013;2(6):174-180.

5. Mandeep, Chitkara n, Goel S. Study to evaluate change of attitude toward acceptance of $\mathrm{NABH}$ guidelines: An intrainstitutional experience. $\mathrm{J}$ Nat Accred Board Hosp Healthcare providers 2014;1:52-55

6. David SN, Valas S. National Accreditation Board For Hospitals and Healthcare Providers (NABH) Standards: A review. Curr Med Issues 2017;15:231-236

7. Patwardhan B. Ayurveda: Finding place in own house. J Ayurveda Integr Med 2012;3:109-10.

8. Hittinahalli V, Golia S. NABH Accreditation and its status in the Country. Al Ameen J Med Sci. 2013;6(1):3-6

9. Chatterjee A. Accreditation of Armed forces hospitals: an 
imperative now. Medical Journal, Armed Forces India. 2017 Jul;73(3):213.

10. Rao GH. Opportunities and challenges in Ayurveda: global perspective. Altern Integr Med. 2017;6(2):239

11. Pramod PS, Vishnu AN. A REVIEW ON SAFETY OF AYURVEDIC MEDICINE.

Facilities.;1:2.

12. Mahindroo GV. Quality Accreditation in AYUSH Healthcare Services. Annals of Ayurvedic medicine. 2017;6(3):83-5.

13. Joseph S. The Effect of Accreditation on Patient Satisfaction in Public Healthcare Delivery: A Comparative Study of Accredited and Non-accredited Hospitals in Kerala. Rajgiri Journal of Social Development. 2018;10(2):27-40.

14. Gluck E. Incredible (Accreditable) India: Trends in Hospital Accreditation Coexistent with the Growth of Medicalveon Rescare Tourism in India. Louis UJ Health L. \& Pol'y. 2007;1:459.

15. Patwardhan K, Pathak J, Acharya R. Ayurveda formulations: A roadmap to address the safety concerns. Journal of Ayurveda and integrative Medicine. 2017 Oct 1;8(4):279-82.

16. Suhail P, Srinivasulu Y. Perception of service quality, satisfaction, and behavioural intentions in Ayurveda Healthcare. Journal of Ayurveda and integrative Medicine. 2020 Dec 11.

17. Rastogi S. Effectiveness, safety, and standard of service delivery: A patient-based survey at a pancha karma therapy unit in a secondary care Ayurvedic hospital. Journal of Ayurveda and integrative medicine. 2011 Oct;2(4):197.

18. Rudrappa S, Agarkhed DV, Vaidya SS. Healthcare Systems: India. InQuality Spine Care 2019 (pp. 211-224). Springer, Cham.

19. GYANI GJ, Krishnamurthy B. The national accreditation board for hospital and health care providers accreditation programme in India. HMA. 2014 Jan 1;50(1):19.

20. Shreedevi D. Hospital preparedness for NABH accreditation with respect to patient rights and education. International Journal of Business Management \& Research (IJBMR) Oct. 2013 Oct;3.

21. Jose R, Sachdeva S. Keeping an eye on future: Medical tourism. Indian Journal of community medicine: official publication of Indian Association of Preventive \& Social Medicine. 2010 Jul;35(3):376.

2. Mishra R, Shailesh K. Making Indian healthcare market a global medical tourism destination. IOSR Journal of Business and Management. 2012 Jul;2(4):23-8.

23. Katoch D, Sharma JS, Banerjee S, Biswas R, Das B, Goswami D, Harwansh RK, Katiyar CK, Mukherjee PK. Government policies and initiatives for development of Ayurveda. Journal of ethnopharmacology. 2017 Feb 2;197:25-31.

24. Mukherjee PK. Evaluation of Indian traditional medicine. Drug Information Journal. 2001 Apr;35(2):623-32.

25. Pathak S. MEDICAL TOURISM IN INDIA. Booksclinic Publishing; 2019 Oct 21.

26. Bhutada S. How Ayushman Bharat can be a boon in uplifting ancient AYUSH medical wisdom. 
Journal of Indian System of Medicine. 2019 Apr 1;7(2):63.

27. Revathi J, Rani SJ. Analysis of Factors Influencing Medical Tourism in India Chennai and its Impacts. Indian Journal of Public Health Research \& Development. 2019 Apr 1;10(4).

28. Bhoyar S, Namburi US, Khode N, Jadhav SS, Suryawanshi MN. BASIC DIMENSIONS OF QUALITY HEALTHCARE IN
ANCIENT SYSTEM OF INDIAN MEDICINE: A CUE FOR CURRENT PRACTICE. Indian Journal of Ayurveda and Pharma Research. 2016 Dec 6.

29. Sharma V, Tomar RS, Ahola NN. Branding India for health and spiritual tourism.

30. Amutha D. Booming Medical Tourism in India. Available at SSRN 2234028. 2013 Mar 15. 